\title{
The role of maternal homocysteine concentration in placenta-mediated complications: findings from the Ottawa and Kingston birth cohort
}

Shazia H. Chaudhry ${ }^{1,2}$, Monica Taljaard ${ }^{1,2}$, Amanda J. MacFarlane ${ }^{3,4}$, Laura M. Gaudet ${ }^{1,2}$, Graeme N. Smith,6, Marc Rodger ${ }^{1,2}$, Ruth Rennicks White ${ }^{1}$, Mark C. Walker ${ }^{1,2}$ and Shi Wu Wen ${ }^{1,2^{*}}$ (i)

\begin{abstract}
Background: Homocysteine is an intermediate metabolite implicated in the risk of placenta-mediated complications, including preeclampsia, placental abruption, fetal growth restriction, and pregnancy loss. Large cohort and case-control studies have reported inconsistent associations between homocysteine and these complications. The purpose of this study was to investigate whether elevated maternal plasma homocysteine concentration in the early to mid-second trimester is associated with an increased risk of placenta-mediated complications. We examined the following potential moderating factors that may explain discrepancies among previous studies: high-risk pregnancy and the MTHFR 677C > T polymorphism.
\end{abstract}

Methods: We analyzed data from participants recruited to the Ottawa and Kingston (OaK) Birth Cohort from 2002 to 2009 in Ottawa and Kingston, Canada. The primary outcome was a composite of any placenta-mediated complication, defined as a composite of small for gestational age (SGA) infant, preeclampsia, placental abruption, and pregnancy loss. Secondary outcomes were, individually: SGA infant, preeclampsia, placental abruption, and pregnancy loss. We conducted multivariable logistic regression analyses with homocysteine as the primary continuous exposure, adjusting for gestational age at the time of bloodwork and explanatory maternal characteristics. The functional form, i.e., the shape of the homocysteine association with the outcome was examined using restricted cubic splines and information criteria (Akaike's/ Bayesian Information Criterion statistics). Missing data were handled with multiple imputation.

Results: 7587 cohort participants were included in the study. Maternal plasma homocysteine concentration was significantly associated (linearly) with an increased risk of both the composite outcome of any placenta-mediated complication ( $p=0.0007)$, SGA ( $p=0.0010)$, severe SGA, and marginally with severe preeclampsia, but not preeclampsia, placental abruption and pregnancy loss. An increase in homocysteine concentration significantly increased the odds of any placenta-mediated complication (odds ratio (OR) for a $5 \mu \mathrm{mol} / \mathrm{L}$ increase: 1.63, 95\% Confidence Interval (Cl) 1.23-2. 16) and SGA (OR 1.76, 95\% Cl 1.25-2.46). Subgroup analyses indicated some potential for modifying effects of the MTHFR 677C>T genotype and high-risk pregnancy, although the interaction was not statistically significant (high-risk subgroup OR 2.37, 95\% Cl 1.24-4.53, $p$-value for interaction $=0.14$ ).

(Continued on next page)

\footnotetext{
* Correspondence: swwen@ohri.ca

${ }^{1}$ The Ottawa Hospital Research Institute, Ottawa, Ontario, Canada

${ }^{2}$ School of Epidemiology and Public Health, University of Ottawa, Ottawa,

Ontario, Canada

Full list of author information is available at the end of the article
}

(c) The Author(s). 2019 Open Access This article is distributed under the terms of the Creative Commons Attribution 4.0 International License (http://creativecommons.org/licenses/by/4.0/), which permits unrestricted use, distribution, and reproduction in any medium, provided you give appropriate credit to the original author(s) and the source, provide a link to the Creative Commons license, and indicate if changes were made. The Creative Commons Public Domain Dedication waiver (http://creativecommons.org/publicdomain/zero/1.0/) applies to the data made available in this article, unless otherwise stated. 
(Continued from previous page)

Conclusions: Our results suggest an independent effect of early to mid-pregnancy elevated maternal homocysteine on placenta-mediated pregnancy complications.

Keywords: Homocysteine, Hyperhomocysteinemia, Pregnancy complication, Placenta, Preeclampsia, Small for gestational age, Placental abruption, Pregnancy loss

\section{Background}

Maternal plasma homocysteine concentration is proposed to be associated with certain pregnancy complications [1]. Based on evidence supporting the role of homocysteine in endothelial dysfunction and as a risk factor for cardiovascular disease, elevated maternal homocysteine is hypothesized to play a role in placenta-mediated pregnancy complications (PMCs), including preeclampsia, placental abruption, intrauterine growth restriction (IUGR), and pregnancy loss [2-5]. All have been linked to abnormal placental vasculature, share a common placental pathophysiology, and have an increased risk to reoccur $[6,7]$.

Within the 1-carbon metabolic cycle, homocysteine is an intermediate metabolite formed in the methionine cycle. Homocysteine can be transmethylated to form methionine, which in turn is converted to S-adenosylmethionine, the main cellular methyl donor from which methyl groups can be transferred to multiple recipient molecules, including DNA and histones. The complex cycle involves key co-enzymes and co-factors including vitamins $\mathrm{B}_{9}$ (folate), $\mathrm{B}_{6}$ and $\mathrm{B}_{12}$. Polymorphisms in genes related to 1-carbon metabolism, as well as various modifiable lifestyle and behavioural factors are associated with elevated homocysteine $[8,9]$.

Studies have reported inconsistent associations between maternal homocysteine, measured at different time points in pregnancy and placenta-mediated complications [10, 11]; even among larger cohort and case-control studies measuring homocysteine from early pregnancy, the associations are inconsistent [12-18]. The discrepancies could be due to moderating factors like high-risk pregnancy and differences in population frequencies of the MTHFR $677 \mathrm{C}>\mathrm{T}$ polymorphism that can lead to moderately elevated homocysteine $[19,20]$. Discrepancies could also arise from different percentile cut-offs used to define elevated homocysteine $[13,14,21]$.

The purpose of this study was to investigate whether elevated maternal plasma homocysteine concentration measured in the early to mid-second trimester of pregnancy is associated with an increased risk of PMCs. Our analytic approach sought to explore potential non-linear effects of homocysteine concentration and other continuous factors so as to retain as much information about the association, which can otherwise be lost through categorizing continuous variables [22]. We also sought to determine whether the association is modified by the MTHFR $677 \mathrm{C}>\mathrm{T}$ genotype and by high-risk pregnancy.

\section{Methods \\ Study design}

Women attending prenatal appointments and planning to deliver at The Ottawa Hospital, the Ottawa region, or the Kingston General Hospital were recruited to the Ottawa and Kingston (OaK) Birth Cohort from 2002 to 2009. Participants were included if between 12 and 20 weeks gestation of a viable singleton or twin pregnancy. For the present study, participants were excluded from the analytic data set if non-singleton, recruited before 12 or after 20 weeks gestation, if they withdrew, were lost to follow-up, or if the pregnancy was terminated.

Details of the cohort study have been previously reported [23]. Briefly, the baseline survey and post-partum follow-up consisted of an interviewer-administered questionnaire and hospital record abstraction. Maternal blood samples were collected at baseline and laboratory personnel were blind to outcomes. Blood samples for homocysteine and MTHFR were collected in $\mathrm{K}_{2}$ EDTA Vacutainer tubes (Becton Dickinson, Lincoln Park, NJ) and for serum folate in serum separator tubes (Becton Dickinson). Samples for plasma were immediately placed on ice and within $30 \mathrm{~min}$ centrifuged in $4{ }^{\circ} \mathrm{C}$ at $3000 \times g$ for $10 \mathrm{~min}$, then aliquoted and stored at $-20^{\circ} \mathrm{C}$. Plasma homocysteine $(\mu \mathrm{mol} / \mathrm{L})$ was measured on the Abbott AxSYM II Immunoassay System (Abbott Laboratories, Abbott Park, IL) using fluorescence polarization immunoassay. Blood samples for serum were centrifuged at $3000 \times g$ for $10 \mathrm{~min}$, then aliquoted and stored at $-20^{\circ}$ C. Serum folate $(\mathrm{nmol} / \mathrm{L})$ was measured using the Beckman Coulter Access 2 and Unicel DxI 800 immunoassay analyzers using manufacturer's reagents (Beckman Coulter, Brea CA). Homocysteine and folate were measured within one month in batches.

\section{Outcomes}

The primary outcome was the composite of placenta-mediated complications (PMCs): small for gestational age (SGA), preeclampsia, placental abruption, and pregnancy loss. The secondary outcomes were individual components of the composite. Additionally we investigated severe SGA <5th percentile and severe preeclampsia. 
A small for gestational age infant had a birth weight less than the 10th or 5th percentile of sex and gestational age-adjusted population standards [24]. Pregnancy loss was intrauterine death before 20 weeks or stillbirth. Preeclampsia was new onset hypertension with proteinuria. Hypertension was a diastolic blood pressure reading greater than or equal to $90 \mathrm{~mm} \mathrm{Hg}$ and proteinuria of $2+$ on a dipstick or proteinuria greater than $300 \mathrm{mg}$ in a 24-h urine collection measured on two separate occasions of at least $6 \mathrm{~h}$ apart. Preeclampsia with delivery prior to 35 weeks gestation was considered severe [25]. Placental abruption was antepartum bleeding with objective evidence either on ultrasound or inspection of the placenta at birth or a pathologic examination of a retro-placental clot [26]. A committee of medical experts blind to participant exposure status independently examined information abstracted from medical records to adjudicate preeclampsia and placental abruption.

\section{Potential risk factors}

Potential confounders, risk factors, and interactions were specified prior to multivariable modeling using knowledge of the subject matter, our analyses of homocysteine determinants in $\mathrm{OaK}$ participants (unpublished), and previous work investigating PMCs [12-14, $21,27]$. We considered the following factors: maternal age, race, education, income, nulliparity, smoking, diabetes, use of hormonal birth control prior to conception, chronic hypertension, history of PMCs, folic acid supplementation, and serum folate. Gestational age at recruitment was abstracted from hospital records.

\section{Statistical analyses}

All statistical analyses were performed in $\mathrm{SAS}^{\circ}$ version 9.4 and RStudio version 0.99.892, $\mathrm{R}$ version 3.2.3 [28] and statistical significance was assessed at the $5 \%$ level. A variable clustering algorithm was used to examine multicollinearity among independent variables. Missing data patterns were visualized and multiple imputation was performed using multivariate imputation by chained equations $[29,30]$. This approach uses sequential regression imputation to create multiple "complete" datasets, a procedure that is flexible and generates multiple predictions for each missing value as a function of all observed data (including auxiliary variables), taking into account the type of variable (i.e., continuous, binary, categorical, ordinal). The number of imputations was set to 10 which is considered an adequate number of imputations [30-32].

\section{Regression analyses}

We conducted multivariable logistic regression analyses to examine the association of plasma homocysteine concentration (as the primary exposure of interest) with PMCs, while adjusting for the identified potential confounders and risk factors. We did not transform homocysteine because log-transformation did not substantially normalize the distribution (Additional file 1: Figure A). Because serum folate is intermediate with respect to folic acid supplementation, analyses were conducted with and without serum folate to note any changes in effect estimates for folic acid supplementation. Changes were also noted for outliers in homocysteine concentration.

Multivariable model building was conducted as follows [22]. An initial model was fit including main effects for all independent variables. Continuous variables, i.e., homocysteine, gestational age, maternal age, BMI, and serum folate were modeled using restricted cubic splines with five knots set at the 5th, 27.5th, 50th, 72.5th, and 95th quantiles. Next, a plot of partial associations referred to as an ANOVA plot, corrected for the number of degrees of freedom, was generated to visualize strong and weak partial associations. The strengths of association informed a decision of how many degrees of freedom to allocate to each variable: strong associations were modeled with greater complexity than weak associations. For example, weaker partial associations in continuous variables were reduced to fewer knots or a linear term, while categorical and ordinal variables were collapsed. Akaike's Information Criterion (AIC) and the Bayesian Information Criterion (BIC) were then used to confirm the allocations [22].

The multivariable logistic regression models were fit using the rms (regression modelling strategies) package [33]. Odds Ratios for continuous variables modelled with restricted cubic splines were estimated comparing the 75th to 25th percentile. The logistic regression model was fit to each imputed dataset and results were combined across the 10 datasets using Rubin's method which computes imputation-adjusted variances and average betas [30, 34]. Analyses of outcomes with a low frequency of events were conducted using penalized maximum likelihood. The best penalty factor was identified by tracing effective AIC for different penalties [22,33].

\section{Subgroup analyses}

Subgroup analyses examined the modifying effect of the MTHFR $677 \mathrm{C}>\mathrm{T}$ genotype and high-risk pregnancy, defined as chronic hypertension, diabetes, history of a PMC, or BMI greater than 35. This was done by including interaction terms with homocysteine and each potential moderator. Subgroup analyses were not conducted for placental abruption and pregnancy loss due to a low number of events.

\section{Results}

Of the 8085 women recruited to the OaK Birth Cohort, 7587 were included in our study (Fig. 1). Descriptive 
characteristics of participants are presented in Table 1. Maternal education and household income were highly correlated; income was dropped from multivariable analyses because education was more strongly associated with the outcomes. ANOVA plots of partial associations revealed relatively strong associations between homocysteine and the outcomes any placenta-mediated complication (PMC) and SGA (Additional file 2). Nevertheless, AIC and BIC values confirmed that for each outcome the models with homocysteine specified as a simple linear term provided the best fit to the data. The final models included both serum folate and folic acid supplementation because excluding folate did not substantially change effect estimates for folic acid supplementation. We identified two outliers with homocysteine $>20 \mu \mathrm{mol} / \mathrm{L}$ that were included in the final models because exclusion yielded similar results (data not shown).

\section{Effect of homocysteine}

Homocysteine concentration was significantly higher in participants with the composite outcome of any PMC, small for gestational age (SGA) infants, and pregnancy loss (Additional file 1: Table A), also demonstrated visually by boxplots of the homocysteine distribution according to pregnancy outcome (Additional file 1: Figure A). In adjusted analyses, higher plasma homocysteine concentration was significantly associated with increased odds of any PMC (Table 2, $p=0.0007$ ), SGA (Table $3, p=0.0010$ ), was marginally associated with preeclampsia $(p=0.07)$, and was not associated with placental abruption, and pregnancy loss (Table 3, 0.99, and 0.16). Additionally, homocysteine was associated with severe SGA $(<5$ th percentile) and marginally with severe preeclampsia (delivery $<35$ weeks gestation) (Table 3, 0.0012, and 0.0595). A $5 \mu \mathrm{mol} / \mathrm{L}$ change in homocysteine concentration, which is approximately 4 SDs of the homocysteine concentration, was associated with a $63 \%$ increased odds of any PMC (Odds Ratio (OR) 1.63, 95\% Confidence Interval (CI) 1.23-2.16) and a 76\% increased odds of SGA (OR 1.76, 95\% CI 1.25-2.46). Serum folate and folic acid supplementation were not associated with the outcomes (Table 2 and Additional file 3: Tables C.1-C.4).

\section{Subgroup analyses}

The results of the subgroup analyses are presented in Tables 4 and 5 . In the subset of 4006 OaK participants with measured genotype, the interaction between MTHFR $677 \mathrm{C}>\mathrm{T}$ and homocysteine was not statistically significant for preeclampsia $(p=0.84)$ but there was some evidence of interaction for any PMC $(p=0.12)$ and for SGA $(p=0.07)$ with associations qualitatively different within each subgroup. Associations in the $\mathrm{CC} / \mathrm{CT}$ subgroups were positive and significant, whereas in TT subgroup associations were negative and not significant, with wide confidence intervals. Figure 2 illustrates these trajectories for the composite outcome with homocysteine. The interaction between high-risk pregnancy and homocysteine was not statistically significant for any PMC and SGA ( $p=0.27$ and $p=0.51$ respectively), but there was some evidence of a moderating effect for preeclampsia $(p=0.14$, Table 5$)$. While the interaction effect

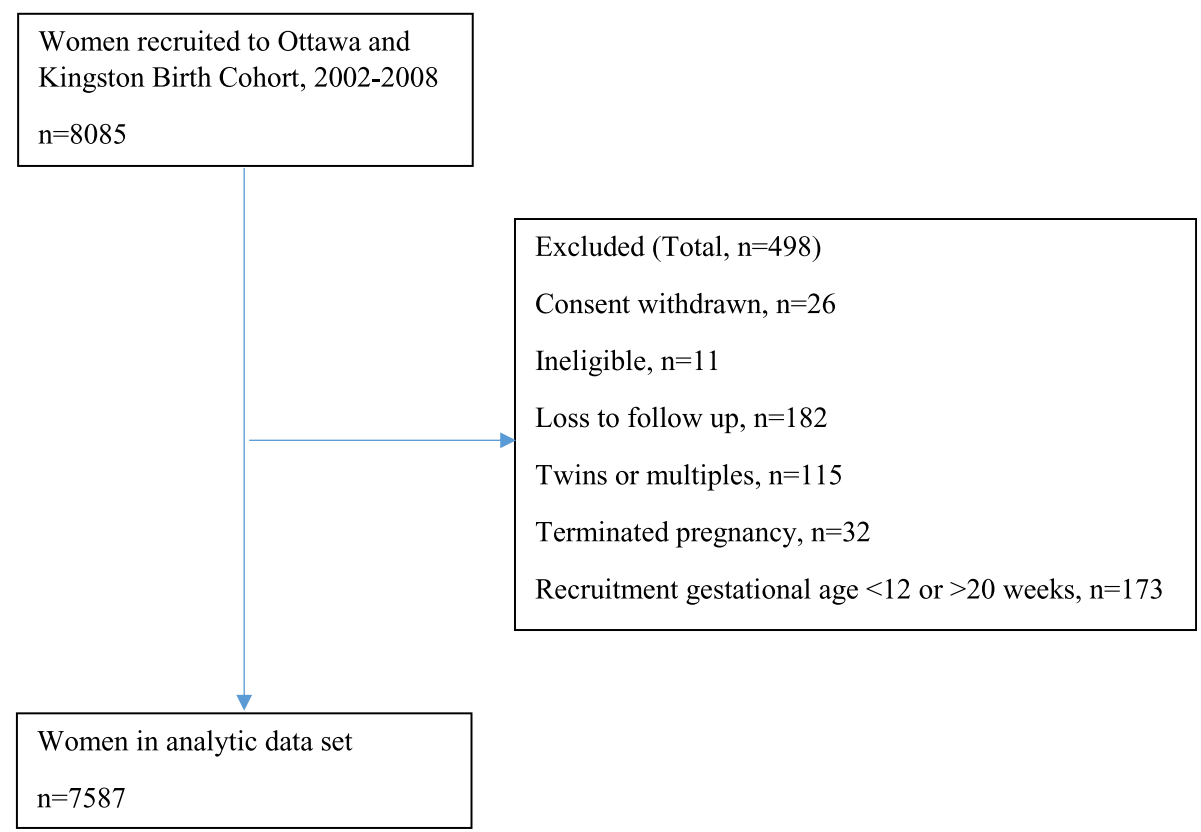

Fig. 1 Participant flow diagram for the analytic dataset 
Table 1 Participant characteristics

\begin{tabular}{|c|c|c|}
\hline Variable & $\begin{array}{l}\text { Frequency } \\
n=7587\end{array}$ & \\
\hline \multicolumn{3}{|l|}{ Age } \\
\hline Mean (SD) & $30.3(5.06)$ & \\
\hline \multicolumn{3}{|l|}{ Race $^{a}$ (missing/unknown $N=415,5.5 \%$ ) } \\
\hline African & 152 & $(2.12 \%)$ \\
\hline Middle eastern & 224 & $(3.12 \%)$ \\
\hline Asian & 422 & $(5.88 \%)$ \\
\hline Caucasian & 6250 & $(87.1 \%)$ \\
\hline Other & 124 & $(1.73 \%)$ \\
\hline \multicolumn{3}{|l|}{ BMI (missing $N=136,1.8 \%$ ) } \\
\hline Mean (SD) & $24.9(5.5)$ & \\
\hline Range & $14.7-61.3$ & \\
\hline \multicolumn{3}{|l|}{$\begin{array}{l}\text { Participant education } \\
\text { (missing } N=7,0.09 \% \text { ) }\end{array}$} \\
\hline Grade school & 153 & $(2.02 \%)$ \\
\hline High school & 962 & $(12.7 \%)$ \\
\hline College/University not completed & 754 & $(10.0 \%)$ \\
\hline $\begin{array}{l}\text { College/University } \\
\text { completed }\end{array}$ & 5711 & $(75.3 \%)$ \\
\hline \multicolumn{3}{|l|}{$\begin{array}{l}\text { Paternal/partner education } \\
\text { (missing } N=95,1.25 \%)\end{array}$} \\
\hline Grade school & 137 & $(1.83 \%)$ \\
\hline High school & 1519 & $(20.3 \%)$ \\
\hline College/University not completed & 590 & $(7.88 \%)$ \\
\hline College/University completed & 5246 & $(70.0 \%)$ \\
\hline \multicolumn{3}{|l|}{$\begin{array}{l}\text { Household income } \\
\text { (missing } N=485,6.4 \% \text { ) }\end{array}$} \\
\hline$<25 k$ & 415 & $(5.84 \%)$ \\
\hline $25 k-<50 k$ & 1188 & $(16.7 \%)$ \\
\hline $50 k-<80 k$ & 2077 & $(29.2 \%)$ \\
\hline$>=80 \mathrm{k}$ & 3422 & $(48.2 \%)$ \\
\hline \multicolumn{3}{|l|}{ MTHFR genotype ${ }^{b}$} \\
\hline CC (wild type) & 1768 & $(44.1 \%)$ \\
\hline CT (heterozygous) & 1760 & $(43.9 \%)$ \\
\hline$\pi$ (mutant) & 478 & (11.9\%) \\
\hline
\end{tabular}

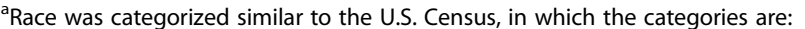
White, Black or African American, American Indian or Alaska Native, Asian (Fareast and Indian subcontinent), and Hawaiian or Pacific Islander. Participants whose response suggested a Central/South American, Latino, Hispanic, or Aboriginal background were classified into the 'Other' category. This follows the U.S. Census Bureau's classification that: "People who identify their origin as Hispanic, Latino, or Spanish may be of any race" [51]

${ }^{\mathrm{b}}$ Measured in a subset of participants $(n=4006)$

(and hence, the difference in association between the high and low-risk subgroups) was not statistically significant at the conventional 5\% level, the odds ratio was higher and statistically significant in the high-risk group (OR 2.84, 95\% CI 1.19 to 6.79 for a $5 \mu \mathrm{mol} / \mathrm{L}$ change in homocysteine concentration) compared to a lower and non-statistically significant $\mathrm{OR}$ in the low-risk group (OR $1.31,95 \%$ CI 0.74 to 2.30 ).

\section{Effects of other factors}

Different groups of risk factors were associated with SGA and preeclampsia (Tables 3, C.1-C.2). A high school or incomplete post-secondary education and smoking were associated with increased odds for any PMC and SGA. Chronic hypertension, diabetes, and history of experiencing a PMC were associated with increased odds for any PMC and preeclampsia.

\section{Discussion \\ Main findings}

We analyzed data from 7587 participants from the Ottawa and Kingston (OaK) Birth cohort. We found that maternal homocysteine concentration in the early to mid-second trimester was associated with increased odds of any placenta-mediated complication (PMC): a composite of small for gestational age (SGA), preeclampsia, placental abruption, and pregnancy loss, and was associated with increased odds of SGA and severe SGA and preeclampsia. In the high-risk subgroup homocysteine was associated with increased odds of preeclampsia.

\section{Strengths and limitations}

To our knowledge, this is the largest cohort study to investigate the association between early to mid-second trimester maternal homocysteine concentration and the risk of placenta-mediated complications. We used multiple imputation to deal with missing values and conducted rigorous multivariable logistic regression analyses designed to explore flexible functional forms of association with homocysteine and other continuous factors, controlling for a wide range of potential confounders.

In most larger studies, homocysteine was dichotomized or grouped to investigate non-linearity and a threshold effect [12, 16]. However, the Hordaland Homocysteine study of several thousand participants suggested that for most conditions including pregnancy complications and adverse pregnancy outcomes, homocysteine exhibits a continuous concentration-response relation $[1,27]$. Thus, one of the main strengths of our study is that we accounted for the functional form, i.e., shape of the association, of homocysteine and other continuous variables in relation to the outcomes of interest, which to the best of our knowledge has not been previously reported.

One of the main limitations of our study is that we did not examine the effect of Vitamins $B_{6}$ and $B_{12}$. In a survey of the Canadian population from 2007 to 2009, Vitamin $B_{12}$ was the main determinant of elevated homocysteine concentration in the folate replete [35]. 
Table 2 Multivariable logistic regression analysis of the association between homocysteine and any placenta-mediated complication a $\left(759\right.$ events $\left.{ }^{b}\right), n=7587$

\begin{tabular}{|c|c|c|c|}
\hline Variable & Odds ratio $(95 \% \mathrm{Cl})$ & & $p$-value ${ }^{c}$ \\
\hline Homocysteine (linear) & & & 0.0007 \\
\hline $5 \mu \mathrm{mol} / \mathrm{L}$ increase & 1.629 & $(1.227,2.161)$ & \\
\hline Age (restricted cubic spline, three knots) & & & 0.0031 \\
\hline 34 versus 27 years & 1.187 & $(1.063,1.325)$ & \\
\hline Race & & & 0.0002 \\
\hline Caucasian versus others & 0.644 & $(0.509,0.814)$ & \\
\hline Education & & & 0.0056 \\
\hline $\begin{array}{l}\text { College/University completed versus } \\
\text { less than completed }\end{array}$ & 0.763 & $(0.630,0.924)$ & \\
\hline Nulliparous & & & $<0.0001$ \\
\hline Yes versus no & 1.941 & $(1.636,2.303)$ & \\
\hline Smoking & & & $<0.0001$ \\
\hline No & Reference & & \\
\hline Second-hand & 0705 & $(0.392,1.268)$ & \\
\hline Med/light smoker ( $<10$ cigarettes per day) & 1.631 & $(1.228,2.166)$ & \\
\hline Heavy smoker ( $\geq 10$ cigarettes per day) & 1.921 & $(1.348,2.737)$ & \\
\hline Diabetes & & & 0.0336 \\
\hline Yes versus no & 1.687 & $(1.041,2.733)$ & \\
\hline BMI (restricted cubic spline, four knots) & & & 0.0499 \\
\hline 27.3 versus $21.1 \mathrm{~kg} / \mathrm{m}^{2}$ & 1.057 & $(0.883,1.265)$ & \\
\hline Hormonal birth control prior to conception & & & 0.3692 \\
\hline No & Reference & & \\
\hline Oral & 0.927 & $(0.784,1.096)$ & \\
\hline Injection or IUD & 0.732 & $(0.436,1.227)$ & \\
\hline Chronic hypertension & & & $<0.0001$ \\
\hline Yes versus no & 2.750 & $(1.687,4.483)$ & \\
\hline $\begin{array}{l}\text { History of PMC (Preeclampsia, placental } \\
\text { abruption, IUGR, stillbirth, loss) }\end{array}$ & & & 0.0110 \\
\hline Yes versus no & 1.359 & $(1.073,1.722)$ & \\
\hline Folic acid supplementation & & & 0.7328 \\
\hline Yes versus no supplementation & 0.943 & $(0.674,1.320)$ & \\
\hline Serum folate (linear) & & & 0.5326 \\
\hline 45.1 versus $30.6 \mathrm{nmol} / \mathrm{L}$ & 1.025 & $(0.949,1.106)$ & \\
\hline $\begin{array}{l}\text { Gestational age at blood work } \\
\text { (restricted cubic spline, four knots) }\end{array}$ & & & 0.0004 \\
\hline 13.7 versus 12.4 weeks & 0.939 & $(0.804,1.095)$ & \\
\hline
\end{tabular}

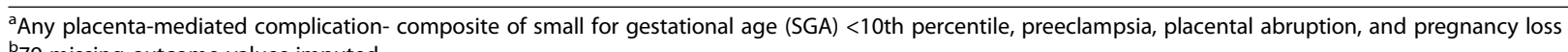
${ }^{\mathrm{b}} 79$ missing outcome values imputed

'Wald test of most meaningful hypotheses, pooled across multiple imputation datasets

We would expect $\mathrm{OaK}$ participants to have adequate Vitamin $\mathrm{B}_{12}$ levels because $85 \%$ were supplementing with multivitamin or prenatal vitamin supplements, which likely contained Vitamin $\mathrm{B}_{12}$. Caffeine or coffee consumption is another homocysteine determinant we did not examine [9], though pregnant women tend to consume less caffeine during pregnancy.

\section{Interpretation}

Other studies have reported an increased risk of SGA associated with elevated homocysteine [12, 36]. In Bergen et al.'s cohort of 5085 participants recruited in the Netherlands from 2002 to 2006, early second trimester homocysteine in the upper versus lower quintile was associated with an increased risk of SGA ( $<5$ th centile) 
Table 3 Summary of multivariable logistic regression analyses of the association between homocysteine and placentamediated complications, $n=7587^{\text {a }}$

\begin{tabular}{|c|c|c|c|}
\hline Outcome variable & \multicolumn{2}{|c|}{ Odds ratio $(95 \% \mathrm{Cl})^{\mathrm{b}}$} & $p$-value ${ }^{c}$ \\
\hline \multicolumn{4}{|c|}{ Any placenta-mediated complication (759 events ${ }^{d}$ ) } \\
\hline Homocysteine (linear) & & & 0.0007 \\
\hline $5 \mu \mathrm{mol} / \mathrm{L}$ increase & 1.629 & $(1.227,2.161)$ & \\
\hline \multicolumn{4}{|l|}{ SGA (512 events $\left.{ }^{d}\right)$} \\
\hline Homocysteine (linear) & & & 0.0010 \\
\hline $5 \mu \mathrm{mol} / \mathrm{L}$ increase & 1.756 & $(1.254,2.458)$ & \\
\hline \multicolumn{4}{|c|}{ SGA $<5$ th percentile $\left(221\right.$ events $^{d}$ ) } \\
\hline Homocysteine (linear) & & & 0.0012 \\
\hline $5 \mu \mathrm{mol} / \mathrm{L}$ increase & 2.022 & $(1.322,3.092)$ & \\
\hline \multicolumn{4}{|l|}{ Preeclampsia (227 events) } \\
\hline Homocysteine (linear) & & & 0.0736 \\
\hline $5 \mu \mathrm{mol} / \mathrm{L}$ increase & 1.546 & $(0.959,2.491)$ & \\
\hline \multicolumn{4}{|c|}{ Severe preeclampsia (43 events) } \\
\hline Homocysteine (linear) & & & 0.0595 \\
\hline $5 \mu \mathrm{mol} / \mathrm{L}$ increase & 1.762 & $(0.978,3.177)$ & \\
\hline \multicolumn{4}{|c|}{ Placental abruption (68 events) } \\
\hline Homocysteine (linear) & & & 0.9851 \\
\hline $5 \mu \mathrm{mol} / \mathrm{L}$ increase & 1.005 & $(0.590,1.711)$ & \\
\hline \multicolumn{4}{|l|}{ Pregnancy loss (85 events) } \\
\hline Homocysteine (linear) & & & 0.1586 \\
\hline $5 \mu \mathrm{mol} / \mathrm{L}$ increase & 1.392 & $(0.879,2.206)$ & \\
\hline
\end{tabular}

${ }^{a}$ Complete results reported in Table 2: any placenta-mediated complication, Additional file 4, and Additional file 3: Table C.1: SGA, Table C.2: Preeclampsia, Table C.3: Placental abruption, and Table C.4: Pregnancy loss

${ }^{\mathrm{b}}$ Models adjusted for maternal age, race, education, parity, smoking, diabetes, $\mathrm{BMI}$, hormonal birth control prior to conception, chronic hypertension, history of a placenta mediated complication, folic acid supplementation, serum folate, and gestational age at blood work

'Wald test of most meaningful hypotheses, pooled across multiple imputation datasets

${ }^{\mathrm{d}} 79$ Missing outcome values imputed
[12]. In Dodds et al.'s cohort of 2119 participants recruited in Nova Scotia, Canada from 2002 to 2005, a study time frame similar to our OaK birth cohort, a homocysteine concentration greater than the 90th percentile was not associated with a risk of SGA [13]. The mean homocysteine concentration in the latter study was lower than Bergen et al. [12], but comparable to our participants' mean homocysteine concentration of $4.8 \mu \mathrm{mol} / \mathrm{L}$. In another study of 65 SGA cases and 358 controls recruited in a Chinese textile factory from 1996 to 1998 , pre-conception homocysteine above the 90th percentile was not associated with an increased risk of SGA [16].These latter two studies dichotomized homocysteine concentration using cut-offs that are not necessarily physiological, which may limit comparability with our findings and those of Bergen et al. [12]

The MTHFR 677C>T genotype qualitatively modified the association of homocysteine with any PMC and SGA. However uncertainty around the negative effect of the TT genotype, likely due to fewer participants the TT subgroup, makes it difficult to interpret the modifying effect. Higher folate intake and status are known to mitigate but not eliminate the effect of this polymorphism on homocysteine concentration [19, 37, 38]. Although approximately $95 \%$ of our sample was consuming a folic acid supplement and white flour and other cereal products in Canada have been fortified with folic acid since the late 1990s, homocysteine concentration was associated with the MTHFR genotype in the OaK cohort. Given the variations in clinical testing for MTHFR genotype in current obstetric practice [39], our study findings suggest testing may be warranted, particularly in high-risk subgroups, for example, those who exhibit comorbidities or a history of complications.

We found that elevated homocysteine was marginally associated with an increased risk of preeclampsia, and that the association was significant in the high-risk subgroup. Others have found no association [12, 14]; for example, Kahn et al.'s nested case-control study with 113 preeclampsia cases and 443 controls recruited in Montreal from 1999 to 2004 [14]. Studies of repeated

Table 4 Multivariable logistic regression analyses examining the moderating effect of MTHFR $677 C>$ T genotype ${ }^{a}$ on the association between homocysteine and placenta-mediated complications, $n=4006$

\begin{tabular}{|c|c|c|c|}
\hline \multirow[t]{2}{*}{ Outcome variable } & \multicolumn{2}{|c|}{ Odds ratio $(95 \% \mathrm{Cl})$ for $5 \mu \mathrm{mol} / \mathrm{L}$ increase ${ }^{b}$} & \multirow{2}{*}{$\begin{array}{l}p- \\
\text { value } \\
c\end{array}$} \\
\hline & $\pi$ & $\mathrm{CC} / \mathrm{CT}$ & \\
\hline Any placenta-mediated complication (395 events ${ }^{d}$ ) & $0.712(0.243,2.083)$ & $1.778(1.159,2.729)$ & 0.1172 \\
\hline SGA (277 events $\left.{ }^{d}\right)$ & $0.639(0.161,2.536)$ & $2.430(1.450,4.073)$ & 0.0714 \\
\hline Preeclampsia (109 events) & $1.174(0.523,2.633)$ & $1.258(0.682,2.322)$ & 0.8439 \\
\hline
\end{tabular}

${ }^{a}$ Homocysteine* MTHFR 677C>T genotype (Factor + higher order factors)

${ }^{\mathrm{b}}$ Model adjusted for maternal age, race, education, parity, smoking, diabetes, BMI, hormonal birth control, chronic hypertension, history of PMC, folic acid supplementation, serum folate, gestational age at blood work

'Wald test of most meaningful hypotheses, pooled across multiple imputation datasets

${ }^{\mathrm{d}} 40$ Missing outcome values imputed 
Table 5 Multivariable logistic regression analyses examining the moderating effect of high-risk pregnancy ${ }^{a}$ on the association between homocysteine and placenta-mediated complications, $n=7587$

\begin{tabular}{|c|c|c|c|}
\hline \multirow[t]{2}{*}{ Outcome variable } & \multicolumn{2}{|c|}{ Odds ratio $(95 \% \mathrm{Cl})$ for $5 \mu \mathrm{mol} / \mathrm{L}$ increase ${ }^{b}$} & \multirow{2}{*}{$\begin{array}{l}p^{-} \\
\text {value } \\
\text { c }\end{array}$} \\
\hline & High-risk & Low-risk & \\
\hline $\begin{array}{l}\text { Any placenta-mediated complication } \\
\left(759 \text { events }{ }^{d} \text { ) }\right.\end{array}$ & $2.368(1.239,4.525)$ & $1.595(1.176,2.163)$ & 0.2714 \\
\hline SGA (512 events $\left.{ }^{d}\right)$ & $2.474(1.050,5.828)$ & $1.821(1.276,2.597)$ & 0.5081 \\
\hline Preeclampsia (227 events) & $2.839(1.187,6.792)$ & $1.308(0.743,2.302)$ & 0.1351 \\
\hline
\end{tabular}

${ }^{\text {a Homocysteine }}$ High-risk pregnancy (Factor + higher order factors)

${ }^{\mathrm{b}}$ Model adjusted for maternal age, race, education, parity, smoking, hormonal birth control, folic acid supplementation, serum folate, gestational age at blood work

'Wald test of most meaningful hypotheses, pooled across multiple imputation datasets

${ }^{d} 79$ Missing outcome values imputed

homocysteine measurement during pregnancy have reported increasing homocysteine concentration during the course of preeclampsia [40]. In a longitudinal analysis of 252 women of whom 49 developed preeclampsia, homocysteine increased in the preeclampsia group independent of B-vitamin $\left(B_{6}, B_{12}\right.$, and folate) and obesity status, while concentrations in the uncomplicated group remained steady [41]. Therefore early homocysteine measurement, as in our study, may pre-date onset of disease and changes in homocysteine. Our finding of a stronger association of homocysteine in severe preeclampsia, marginally significant with fewer outcome events, also suggests a role of homocysteine earlier in pregnancy when severity is increased.

Some studies have, however, reported an increased risk of preeclampsia associated with higher homocysteine concentrations [13, 42-45]. Many of these studies were conducted during a time period before routine peri-conceptional folic acid supplementation and/or mandatory folic acid fortification (i.e., the early to mid-1990s) [42-44], or were conducted in countries without mandatory folic acid fortification [45-47]. This suggests that where folate intake is lower, homocysteine levels would tend to be higher and therefore homocysteine might play a greater role, earlier on, in the development of preeclampsia.

We report the association of the range of potential confounders with the composite and individual outcomes. Our results, although exploratory in this regard, demonstrated a greater role of diabetes and chronic hypertension in the development of preeclampsia compared to SGA. In a clinical opinion paper, Ness and Sibai [48] hypothesized that the maternal syndrome observed in preeclampsia develops in the presence of abnormal placentation that interacts with maternal metabolic syndrome, and that fetal growth restriction develops in the absence of metabolic syndrome. Our findings of increased odds

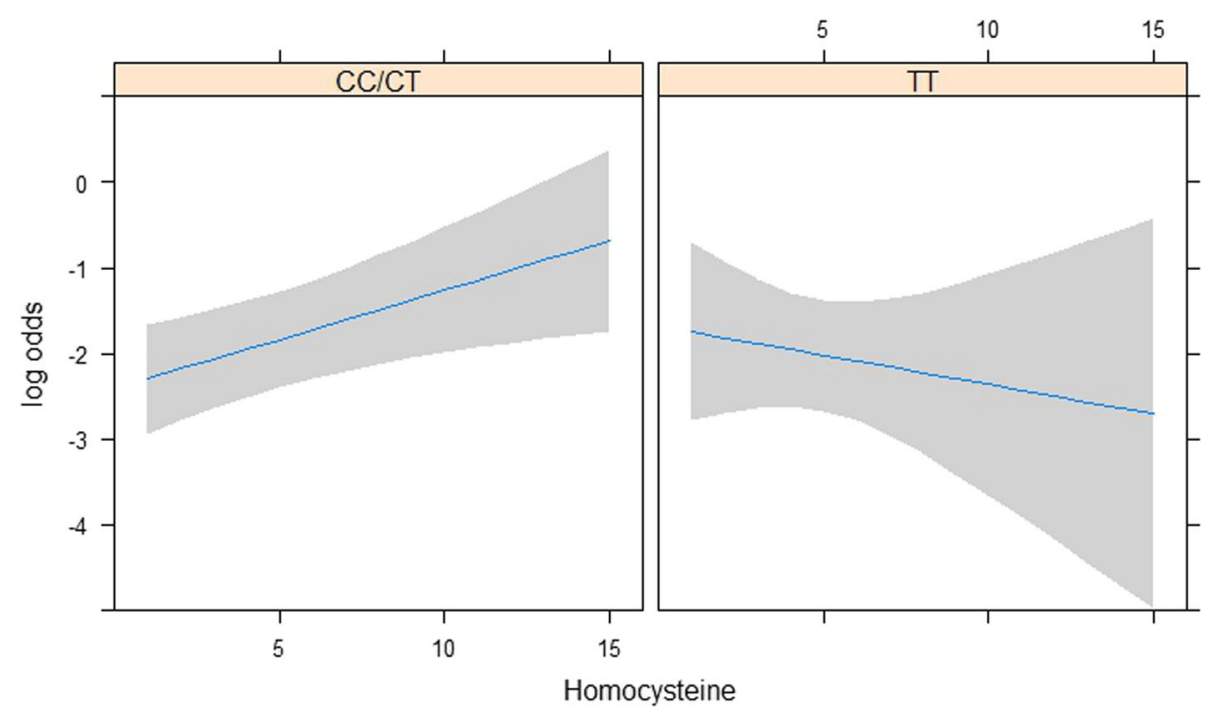

Fig. 2 Modelled association between plasma homocysteine (linear) and any placenta-mediated complication, by MTHFR 677C>T genotype CC/CT (wild type and heterozygous) and TT (mutant). Shaded area represents 95\% Cl 
of preeclampsia in the high-risk subgroup also lend support to this hypothesized role of developing endothelial dysfunction in preeclampsia.

In our study elevated homocysteine concentration was not associated with an increased risk of placental abruption and pregnancy loss, but a greater number of events would be necessary to confirm an association. Some studies have found no association of homocysteine with early pregnancy loss $[15,17,49]$. However, one-time early pregnancy losses are characteristically different from recurrent early pregnancy losses and losses throughout pregnancy [10].

\section{Conclusions}

In summary, our results support an independent effect of early to mid-pregnancy elevated homocysteine on placenta-mediated pregnancy complications. Our findings are comparable with similar large studies; high-risk pregnancy and potentially the MTHFR $677 \mathrm{C}>\mathrm{T}$ genotype may contribute to some of the observed differences between studies. As with ongoing investigations into the role of homocysteine in cardiovascular disease, large Mendelian randomization studies could further confirm the etiological role of homocysteine in placenta-mediated pregnancy complications [50].

\section{Additional files}

Additional file 1: Homocysteine distribution in the entire sample and by outcome. (DOCX $145 \mathrm{~kb}$ )

Additional file 2: ANOVA plots of partial associations from saturated model for each outcome. (DOCX $433 \mathrm{~kb}$ )

Additional file 3: Complete tables of results for the multivariable logistic regression analyses. (DOCX $27 \mathrm{~kb}$ )

Additional file 4: Modelled associations of restricted cubic spline functions. (DOCX $1090 \mathrm{~kb}$ )

\section{Abbreviations}

AIC: Akaike's information criterion; BIC: Bayesian information criterion; BMI: Body mass index; IUGR : Intrauterine growth restriction; MTHFR: Methylenetetrahydrofolate reductase; OaK: Ottawa and Kingston; PMC: Placenta-mediated complication; SGA: Small for gestational age

\section{Acknowledgements}

S. H. Chaudhry is a recipient of a PhD Scholarship from the CIHR-Quebec Training Network in Perinatal Research (QTNPR).

\section{Funding}

This study was supported by grants from the Canadian Institutes of Health Research (Grant MOP 53188 and 82802, Grant FDN 148438). The funding agency had no involvement in study design; in the collection, analysis and interpretation of data; in the writing of the report; and in the decision to submit the article for publication.

\section{Availability of data and materials}

The datasets used and/or analysed during the current study are available from the corresponding author on reasonable request.

\section{Authors' contributions}

SW, MW, RRW, GS, and MR are lead investigators of the Ottawa and Kingston (OaK) Birth Cohort. SC, SW, and MT designed the study. SC analyzed the patient data and wrote the draft manuscript. SC, SW, MT, and AM were involved in interpretation of the data. LG, MW, RRW, GS, and MR critically revised the manuscript and contributed to the final version. All authors read and approved the final manuscript.

\section{Ethics approval and consent to participate}

Ethics approval for the Ottawa and Kingston (OaK) Birth Cohort was obtained from the Ottawa Health Science Network Research Ethics Board (protocol 2002343-01H and 2007034-01H). Eligible participants provided written informed consent. Ethics approval for this secondary analysis was obtained from the OHSN-REB (20160163-01H) on 31 May 2016.

Consent for publication

'Not applicable'.

\section{Competing interests}

The authors declare that they have no competing interests.

\section{Publisher's Note}

Springer Nature remains neutral with regard to jurisdictional claims in published maps and institutional affiliations.

\section{Author details}

${ }^{1}$ The Ottawa Hospital Research Institute, Ottawa, Ontario, Canada. ${ }^{2}$ School of Epidemiology and Public Health, University of Ottawa, Ottawa, Ontario, Canada. ${ }^{3}$ Nutrition Research Division, Health Canada, Ottawa, Ontario, Canada. ${ }^{4}$ Department of Biochemistry, Microbiology and Immunology, University of Ottawa, Ottawa, Ontario, Canada. ${ }^{5}$ Department of Obstetrics \& Gynaecology, Division of Maternal-Fetal Medicine, Queen's University, Kington, Ontario, Canada. ${ }^{6}$ Kingston General Hospital Research Institute, Kington, Ontario, Canada.

Received: 22 June 2018 Accepted: 11 February 2019

Published online: 19 February 2019

\section{References}

1. Vollset SE, Refsum H, Irgens LM, Emblem BM, Tverdal A, Gjessing HK, et al. Plasma total homocysteine, pregnancy complications, and adverse pregnancy outcomes: the Hordaland homocysteine study. Am J Clin Nutr. 2000;71(4):962-8.

2. McCully KS. Vascular pathology of homocysteinemia: implications for the pathogenesis of arteriosclerosis. Am J Pathol. 1969;56(1):111-28.

3. McCully KS. Homocysteine, vitamins, and vascular disease prevention. Am J Clin Nutr. 2007:86:1563-8.

4. Wald DS, Morris JK, Wald NJ. Reconciling the evidence on serum homocysteine and ischaemic heart disease: a meta-analysis. PLoS One. 2011; 6(2):e16473.

5. Wald DS, Bestwick JP, Wald NJ. Homocysteine as a cause of ischemic heart disease: the door remains open. Clin Chem. 2012;58(10):1488-90.

6. Ananth CV, Peltier MR, Chavez MR, Kirby RS, Getahun D, Vintzileos AM Recurrence of ischemic placental disease. Obstet Gynecol. 2007;110(1):128-33.

7. Ananth CV. Ischemic placental disease: a unifying concept for preeclampsia, intrauterine growth restriction, and placental abruption. Semin Perinatol. 2014:38(3):131-2.

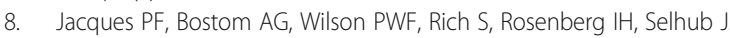
Determinants of plasma total homocysteine concentration in the Framingham offspring cohort. Am J Clin Nutr. 2001;73(3):613-21.

9. Nygård O, Refsum H, Ueland PM, Vollset SE. Major lifestyle determinants of plasma total homocysteine distribution: the Hordaland homocysteine study. Am J Clin Nutr. 1998;67(2):263-70.

10. Ray JG, Laskin CA. Folic acid and homocyst(e)ine metabolic defects and the risk of placental abruption, pre-eclampsia and spontaneous pregnancy loss: a systematic review. Placenta. 1999;20(7):519-29.

11. Mignini LE, Latthe PM, Villar J, Kilby MD, Carroli G, Khan KS. Mapping the theories of preeclampsia: the role of homocysteine. Obstet Gynecol. 2005; 105(2):411-25

12. Bergen NE, Jaddoe WW, Timmermans S, Hofman A, Lindemans J, Russcher $\mathrm{H}$, et al. Homocysteine and folate concentrations in early pregnancy and 
the risk of adverse pregnancy outcomes: the generation R study. BJOG. 2012;119(6):739-51.

13. Dodds L, Fell DB, Dooley KC, Armson BA, Allen AC, Nassar BA, et al. Effect of homocysteine concentration in early pregnancy on gestational hypertensive disorders and other pregnancy outcomes. Clin Chem. 2008;54(2):326-34.

14. Kahn SR, Platt R, McNamara H, Rozen R, Chen MF, Genest J Jr, et al. Inherited thrombophilia and preeclampsia within a multicenter cohort: the Montreal preeclampsia study. Am J Obstet Gynecol. 2009;200(2):151.e1-9.

15. Ronnenberg AG, Venners SA, X X, Chen C, Wang L, Guang W, et al. Preconception B-vitamin and homocysteine status, conception, and early pregnancy loss. Am J Epidemiol. 2007;166(3):304-12.

16. Ronnenberg AG, Goldman MB, Chen D, Aitken IW, Willett WC, Selhub J, et al. Preconception homocysteine and B vitamin status and birth outcomes in Chinese women. Am J Clin Nutr. 2002;76(6):1385-91.

17. Ronnenberg AG, Goldman MB, Chen D, Aitken IW, Willett WC, Selhub J, et al. Preconception folate and vitamin B (6) status and clinical spontaneous abortion in Chinese women. Obstet Gynecol. 2002;100(1):107-13.

18. Maged AM, Saad H, Meshaal H, Salah E, Abdelaziz S, Omran E, et al. Maternal serum homocysteine and uterine artery Doppler as predictors of preeclampsia and poor placentation. Arch Gynecol Obstet. 2017;296(3):475-82.

19. Clarke R, Bennett DA, Parish S, Verhoef P, Dötsch-Klerk M, Lathrop M, et al. Homocysteine and coronary heart disease: meta-analysis of MTHFR casecontrol studies, avoiding publication bias. PLoS Med. 2012;9(2):e1001177.

20. Sibani S, Leclerc D, Weisberg IS, O'Ferrall E, Watkins D, Artigas C, et al. Characterization of mutations in severe methylenetetrahydrofolate reductase deficiency reveals an FAD-responsive mutation. Hum Mutat. 2003;21:509-20.

21. Wen SW, Chen X-K, Rodger M, White RR, Yang Q, Smith GN, et al. Folic acid supplementation in early second trimester and the risk of preeclampsia. Am J Obstet Gynecol. 2008;198(1):45.e1-7.

22. Harrell FE. Regression modeling strategies with applications to linear models, logistic and ordinal regression, and survival analysis. Second Edi Springer Series in Statistics; 2015.

23. Walker MC, Finkelstein SA, Rennicks White R, Shachkina S, Smith GN, Wen SW, et al. The Ottawa and Kingston (OaK) birth cohort: development and achievements. J Obstet Gynaecol Canada. 2011;33(11):1124-33.

24. Kramer MS, Platt RW, Wen SW, Joseph KS, Allen A. A New and Improved population-based birth weight for gestational age. Pediatrics. 2001;108(2):e35.

25. Turner JA. Diagnosis and management of pre-eclampsia: an update. Int Women's Health. 2010;2(1):327-37.

26. Macdonald PC, Gant NF, Leveno KJ, Gilstrap LC, Hankins GDF, Clark SL, et al. Williams obstetrics. Cunningham FG, Williams JW, editors. Appleton \& Lange; 1997. viii, 1448:ill.

27. Refsum H, Nurk E, Smith AD, Ueland PM, Gjesdal CG, Bjelland I, et al. The Hordaland homocysteine study: a community-based study of homocysteine, its determinants, and associations with disease. J Nutr. 2006;136:1731S-40S.

28. R Core Team. R: A Language and Environment for Statistical Computing. Vienna: R Foundation for Statistical Computing; 2016. Available from: https://www.r-project.org/

29. Templ M, Alfons A, Kowarik A, Prantner B. VIM: Visualization and Imputation of Missing Values. 2016, R package version 4.5.0. Available from: https://cran. r-project.org/package=VIM

30. van Buuren S, Groothuis-oudshoorn K. Mice: multivariate imputation by chained equations in R. J Stat Softw. 2011:45(3):1-67.

31. Rubin DB. Multiple imputation for survey non-response. New York: Wiley; 1987.

32. Von Hippel PT. How many imputations are needed? A comment on Hershberger and fisher (2003). Struct Equ Model. 2005;12(2):334-5.

33. Frank E Harrell Jr. rms: Regression Modeling Strategies. 2016, R package version 4.5-0. Available from: https://cran.r-project.org/package=rms

34. Frank E Harrell Jr, With contributions from Charles Dupont and many others. Hmisc: Harrell Miscellaneous. 2016, R package version 3.17-4. Available from: https://cran.r-project.org/package=Hmisc

35. MacFarlane AJ, Greene-finestone LS, Shi Y. Vitamin B-12 and homocysteine status in a folate-replete population: results from the Canadian health measures survey. Am J Clin Nutr. 2011:94:1079-87.

36. Furness $D$, Fenech $M$, Dekker $G$, Khong TY, Roberts C, Hague W. Folate, vitamin B12, vitamin B6 and homocysteine: impact on pregnancy outcome. Matern Child Nutr. 2011;9(2):155-66

37. Holmes MV, Newcombe P, Hubacek JA, Sofat R, Ricketts SL, Cooper J, et al. Effect modification by population dietary folate on the association between MTHFR genotype, homocysteine, and stroke risk: a meta-analysis of genetic studies and randomised trials. Lancet. 2011;378:584-94.
38. Crider KS, Zhu J, Hao L, Yang Q, Yang TP, Gindler J, et al. MTHFR 677C> T genotype is associated with folate and homocysteine concentrations in a large, population-based, double-blind trial of folic. Am J Clin Nutr. 2011; 93(6):1365-72

39. Long S, Goldblatt J. MTHFR genetic testing: controversy and clinical implications. Aust Fam Physician. 2016;45(4):237-40.

40. Roes EM, Hendriks JCM, Raijmakers MTM, Steegers-Theunissen RPM, Groenen P, Peters WHM, et al. A longitudinal study of antioxidant status during uncomplicated and hypertensive pregnancies. Acta Obstet Gynecol Scand. 2006;85(2):148-55.

41. Lopez-Alarcon MI, Montalvo-Velarde I, Vital-Reyes VS, Hinojosa-Cruz JC, Leanos-Miranda A, Martinez-Basila A. Serial determinations of asymmetric dimethylarginine and homocysteine during pregnancy to predict preeclampsia: a longitudinal study. BJOG. 2015;122(12):1586-92.

42. Sorensen TK, Malinow MR, Williams MA, King IB, Luthy DA. Elevated secondtrimester serum homocyst(e)ine levels and subsequent risk of preeclampsia. Gynecol Obstet Investig. 1999;48(2):98-103.

43. Cotter AM, Molloy AM, Scott JM, Daly SF. Elevated plasma homocysteine in early pregnancy: a risk factor for the development of severe preeclampsia. Am J Obstet Gynecol. 2001;185(4):781-5.

44. Cotter AM, Molloy AM, Scott JM, Daly SF. Elevated plasma homocysteine in early pregnancy: a risk factor for the development of nonsevere preeclampsia. Am J Obstet Gynecol. 2003;189(2):391-6.

45. Cheng P-J, Huang S-Y, Su S-Y, Hsiao C-H, Peng H-H, Duan T. Prognostic value of cardiovascular disease risk factors measured in the first-trimester on the severity of preeclampsia. Medicine (Baltimore). 2016:95(5):e2653.

46. Onalan R, Onalan G, Gunenc Z, Karabulut E. Combining 2nd-trimester maternal serum homocysteine levels and uterine artery Doppler for prediction of preeclampsia and isolated intrauterine growth restriction. Gynecol Obstet Investig. 2006;61:142-8.

47. Wadhwani NS, Patil W, Mehendale SS, Wagh GN, Gupte SA, Joshi SR. Increased homocysteine levels exist in women with preeclampsia from early pregnancy. J Matern Fetal Neonatal Med. 2016;29:2719-25.

48. Ness RB, Sibai BM. Shared and disparate components of the pathophysiologies of fetal growth restriction and preeclampsia. Am J Obstet Gynecol. 2006;195(1):40-9.

49. Hoffman ML, Scoccia B, Kurczynski TW, Shulman LP, Gao W. Abnormal folate metabolism as a risk factor for first-trimester spontaneous abortion. J Reprod Med. 2008;53(3):207-12.

50. Chen Z, Chen J, Collins R, Guo Y, Peto R, Wu F, et al. China Kadoorie biobank of 0.5 million people: survey methods, baseline characteristics and long-term follow-up. Int J Epidemiol. 2011;40:1652-66.

51. United States Census Bureau. [cited 2016 Jul 2]. Available from: http:/www. census.gov/topics/population/race/about.htm

\section{Ready to submit your research? Choose BMC and benefit from:}

- fast, convenient online submission

- thorough peer review by experienced researchers in your field

- rapid publication on acceptance

- support for research data, including large and complex data types

- gold Open Access which fosters wider collaboration and increased citations

- maximum visibility for your research: over $100 \mathrm{M}$ website views per year

At $\mathrm{BMC}$, research is always in progress.

Learn more biomedcentral.com/submission 